\title{
NUTRITIVE INTAKE OF OMEGA-3 FATTY ACIDS AND MATERNITY
}

\author{
Darina N. Hristova, Gabriela S. Tsankova, Neli M. Ermenlieva, Tatina T. \\ Todorova. \\ Department of Preclinical and Clinical Sciences, Faculty of Pharmacy, Medical \\ University - Varna, Bulgaria.
}

\section{ABSTRACT}

Introduction: Pregnancy and lactation are physiological conditions, which put the female organism into a serious ordeal. The satisfaction of the nutritive needs during maternity plays a significant role in the favorable end of pregnancy and for the health of both mother and infant. A significant number of studies prove the importance of the essential fatty acids for mother's and baby's health. During this period the needs of fats do not exceed, but the requirements to them increase.

Aim: To study the nutritive intake of omega-3 fatty acids (n-3 FA) in pregnant women in Varna, Bulgaria and to determine if there is a risk for nutritive deficiency.

Materials and methods: A questionnaire (Food Frequency Questionnaire) about the consumption of foods sources of n-3 FA was distributed among 350 pregnant and nursing women in Varna, Bulgaria.

Results and discussion: Less than $40 \%$ of the responders regularly consume foods, sources of polyunsaturated fatty acid: fish, walnuts, linseeds, etc. Only $9,3 \%$ of the young mothers take dietary supplements with n-3 FA.

Conclusion: A low nutritive intake of essential fats was found. The receiving of PUFA dietary supplements is not popular among the Bulgarian mothers. Over half of the pregnant and nursing women are at risk of non-adequate intake of n-3 FA.

Keywords: n-3 fatty acids, polyunsaturated fatty acids, nutritive intake, pregnancy and lactation

\section{INTRODUCTION}

Pregnancy and breastfeeding are physiological conditions, which put the women's organism into a serious ordeal. The satisfaction of the nutritive needs during maternity is significant for the favorable end of pregnancy and for the health of both mother and infant. Prenatal feeding of the fetus has a leading role for development of the nervous system and brain growth [1]. The early neurological development of infants correlates positively with the content of long chain polyunsaturated fatty acids (LCPUFA) of the omega-3 group (n-3 FA). Omega-3 FA cannot be synthesized in human's organism, but they are part of the cell membranes of each cell. While the other main compounds of membranes - proteins are genetically determined, PUFA depend entirely on the nutritional intake. Investigations in primates and newly born children show that one of the most important PUFA - the docosahexaenoic acid (DHA) is essential for the development and normal functioning of retina and brain. Studies prove that during the last trimester of pregnancy and during breastfeeding, there is an increased transfer of DHA from mother to fetus and accumulation of DHA in the child's brain and retina [1]. The presence of essential fats in mother's milk during the first weeks of life of the newborn may have crucial influence over its brain development [2]. The fatty-acid composition of mother's milk varies according to the nutritive intake and DHA status of the mother. Unfortunately, mother's milk may contain low concentrations of DHA and not to meet the needs of the newborn.

Blood testing of umbilical cord shows that the optimal intake of n-3 FA during pregnancy has a great impact on the DHA-status of the baby. The highest needs of omega3 for the growing brain of the fetus are during the last trimester of pregnancy and the first year of birth. These fats improve vision, cognitive abilities and immunity of children and decrease the risk of allergies. In addition, omega3 fats decrease the risk of premature birth and low birth weight of the newborn, and help to have a full time pregnancy, especially if it is risky or multiple [3, 4]. An additional benefit for the mother is that PUFA lowers the risk of after-birth depression. Several clinical and epidemiological studies show that the deficiency of DHA (because of the low nutritive intake or diminished tissue levels after birth and breastfeeding) can lead to the occurrence of this severe multifactorial disturbance [5].

\section{AIM}

The objective of our work is to study the nutritive intake of omega-3 fatty acids in pregnant women in Varna, Bulgaria and to determine if there is a risk for nutritive deficiency.

\section{MATERIALS AND METHODS}

A questionnaire (Food Frequency Questionnaire) about the consumption of foods - sources of n-3 FA was distributed among 350 pregnant and nursing women. 


\section{RESULTS AND DISCUSSION}

Usually, the diet of a pregnant woman corresponds to the growing energy needs, but not always meets the increased needs of PUFA. The insufficient, as well as the excessive intake of n-3 FA, can have unfavourable consequences for baby's growth and development [6]. In the health regulation of Republic of Bulgaria, there is no recommended intake of n-3 FA for pregnant and nursing mothers [7]. According to the national recommendations in Canada, pregnant women in the last trimester must take $0,16 \mathrm{mg}$ n-3 FA daily while nursing women during the first 6 months after the birth $-0,25 \mathrm{mg}$. The best source of long chain n-3 FA are sea and ocean fishes - salmon, herring, mackerel, etc. Fish brings LHPUFA - DHA (22:6) and eicozapentaenic (EPÀ) (20:5) fatty acids. Complete sources of n-3 FA are nuts (walnuts) and seeds (linseed, sesame seeds). The necessary amount of LHPUFA can be provided by 2 fish servings (240-340 g) weekly, as well as by regular consumption of traditional Bulgarian walnuts.

We found that the linseed and flax oil were consumed sporadically in Bulgaria and they could not be regarded as a source of useful fats.

Less than $40 \%$ of the responders regularly consumed foods, sources of PUFA (fish, walnuts). Our results showed that only $38 \%$ of the young mothers consumed two servings of n-3 FA foods (fish, nuts) weekly, and $36 \%$ consumed them only once. A significant part of pregnant women affirmed not to consume fish $(26 \%)$ because of scent sensitivity or fear of contamination.

After a careful assessment of the risk of contamination with mercury, the US Food and Drug Administration recommends pregnant, nursing women and children to avoid the consumption of big predatory fishes (shark, swordfish, tuna, king mackerel) and to limit the consumption of other fishes to $340 \mathrm{~g}$ weekly [8]. The recommendation of UK Scientific Advisory Committee on Nutrition is almost the same - up to 2 portions of $140 \mathrm{~g}$ fatty fish weekly $[9,10]$.

Our study showed that $12 \%$ of women avoided nuts because of their caloric value. Eleven percent of all women were in the most unfavourable situation consuming neither fish nor nuts. The alternative for these women can be the dietary supplementation with n-3 FA. It is found that the supplement intake of cod-liver oil, rich of DHA, led to significantly increase of the plasma concentration of DHA in mother's and umbilical cord blood samples [11]. Such supplementation can improve the n-3 FA status of the fetus and can limit the depletion of mother's depots. Only $9,3 \%$ of the young mothers use products with cod-liver oil, despite their presence on market. The majority of the studied women assumed as not necessary to take such kind of supplements, especially when they have not been prescribed by the observing doctor.

\section{CONCLUSION}

PUFA have been present in the diet of humans for many centuries. The contemporary farming and globalization of the food market contribute in a high level for the insufficient intake of these essential nutrients, and the deficiency of n-3 FA is a common condition, including in women of childbearing age. PUFA have significant importance for the growth, development and health during the whole life cycle and must be included in the diet of all people [12]. The provision of adequate amount of n-3 FA is especially important in the following cases: last trimester of pregnancy; the first $6-12$ months after the birth; in premature babies; in multiple pregnancy; if there is a risk for premature delivery; in women with a short gap between pregnancies which does not allow recovery of the mother's depots of essential fats [13].

The present study found a low nutritive intake of n3 FA among the pregnant women in Varna, Bulgaria. Unfortunately, the intake of dietary supplements with PUFA is not popular among the Bulgarian mothers. Over half of the pregnant and nursing women are at risk for inadequate intake of n-3 FA. There is a risk for the development of the fetus as well as for mother's health.
Abbreviation list:
FA - fatty acids
PUFA - polyunsaturated fatty acid
LCPUFA - long chain polyunsaturated fatty acid
DHA - docosahexaenoic acid
FFQ - food frequency questionnaire
FDA - food and drug administration

\section{REFERENCES:}

1. Lundqvist-Persson C, Lau G, Nordin P, Strandvik B, Sabel KG. Early behaviour and development in breastfed premature infants are influenced by omega- 6 and omega- 3 fatty acid status. Early Hum Dev. 2010 Jul;86(7): 407-12. [PubMed] [CrossRef]

2. Simopoulos AP. Omega-3 fatty acidsin health and disease and in growth and development. Am J Clin Nutr. 1991 Sep;54:438-63. [PubMed]

3. Olsen SF, Sorensen JD, Secher
NJ, Hedegaard M, Henriksen TB, Hansen HS, et al. Randomised controlled trial of effect of fish-oil supplementation on pregnancy duration. Lancet. 1992 Apr 25;339(8800):10037. [PubMed]

4. Smuts CM, Huang M, Mundy D, Plasse T, Major S, Carlson SE. A randomized trial of docosahexaenoic acid supplementation during the third trimester of pregnancy. Obstet Gynecol. 2003 Mar;101(3):469-79.
[PubMed]

5. Levant B. N-3 (omega-3) Fatty acids in postpartum depression: implications for prevention and treatment. Depress Res Treat. 2011;2011:467349. [PubMed] [CrossRef]

6. Church MW, Jen KL, Jackson DA, Adams BR, Hotra JW. Abnormal neurological responses in young adult offspring caused by excess omega- 3 fatty acid (fish oil) consumption by the mother during pregnancy and lactation. 
Neurotoxicol Teratol. 2009 JanFeb;31(1):26-33. [PubMed] [CrossRef]

7. Ordinance No. 23 of 19 July 2005 for the physiological norms of nutrition of the population, Ministry of Health. DV, issue No. 63 (2 August 2005). [In Bulgarian].

8. FDA/CFSAN. Consumer advisory: An important message for pregnant women and women of childbearing age who may become pregnant about the risks of mercury in fish. March 2001. [Internet]

9. Institue of Medicine of the $\mathrm{Na}$ tional Academies. Dietary Reference Intakes for Energy, Carbohydrate, Fiber, Fat, Fatty Acids, Cholesterol, Protein, and Amino Acids. National
Academies Press, Washington, DC. 2005. [Internet]

10. Scientific Advisory Committee on Nutrition (SACN). Advice on fish consumption: benefits and risk. Committee on Toxicity. 2004. [Internet]

11. Krauss-Etschmann S, Shadid R, Campoy C, Hoster E, Demmelmair H, Jimines M, et al. Effects of fish-oil and folate supplementation of pregnant women on maternal and fetal plasma concentrations of docosahexaenoic acid and eicosapentaenoic acid: a European randomized multicenter trial. Am J Clin Nutr. 2007 May; 85(5): 1392-400. [PubMed]

12. van der Merwe LF, Moore SE,
Fulford AJ, Halliday KE, Drammeh S, Young S, et al. Long-chain PUFA supplementation in rural African infants: a randomized controlled trial of effects on gut integrity, growth, and cognitive development. Am J Clin Nutr. 2013 Jan;97(1):45-57. [PubMed] [CrossRef] 13. Bonham MP, Duffy EM, Wallace JM, Robson PJ, Myers GJ, Davidson PW, et al. Habitual fish consumption does not prevent a decrease in LCPUFA status in pregnant women (the Seychelles Child Development Nutrition Study). Prostaglandins Leukot Essent Fatty Acids. 2008 Jun;78(6):343-50. [PubMed] [CrossRef]

Please cite this article as: Hristova DN, Tsankova GS, Ermenlieva NM, Todorova TT. Nutritive intake of omega-3 fatty acids and maternity. J of IMAB. 2018 Apr-Jun;24(2):1985-1987. DOI: https://doi.org/10.5272/jimab.2018242.1978

Received: 09/11/2017; Published online: 18/04/2018

Address for correspondence:

Darina Naydenova Hristova,

Department of Preclinical and Clinical Sciences, Faculty of Pharmacy, Medical University - Varna,

3, Bregalniza Str., 9002 Varna, Bulgaria

E-mail: dary_nay@mail.bg 